\title{
Peningkatan Kompetensi Guru dan Siswa SMK Melalui Pelatihan Kompetensi Kejuruan Teknologi Otomotif
}

\author{
Toto Sugiarto $^{1 *}$, Bahrul Amin ${ }^{1}$, Wawan Purwanto ${ }^{1}$, Ahmaf Arif ${ }^{1}$, Dwi Sudarno Putra ${ }^{1}$ \\ ${ }^{1}$ Jurusan Teknik Otomotif, Fakultas Teknik, Universitas Negeri Padang \\ *Corresponding author, e-mail: totosugiarto@ft.unp.ac.id
}

\begin{abstract}
Abstrak - Sekolah Menengah Kejuruan bertujuan untuk mampu menyiapkan peserta didik yang kreatif, menguasai ilmu pengetahuan dan teknologi, serta memiliki kompetensi yang sesuai dengan tuntutan dunia kerja. Kualitas lulusan SMK tidak hanya ditentukan oleh faktor individu dari siswa itu sendiri, akan tetapi juga sangat ditentukan oleh faktor dari luar, salah satunya komptensi pendidikan yang bisa menyiapkan lulusan sesuai dengan tuntutan dunia kerja. Program Ipteks bagi Masyarakat (IbM) bertujuan untuk memberikan pelatihan Kompetensi Kejuruan Teknologi Otomotif bagi guru dan siswa SMK di kabupaten Solok, kegiatan IbM dengan tema Peningkatan Kompetensi Kejuruan Teknologi Otomotif bagi Guru dan Siswa SMK, dapat meningkatkan pengetahuan dan keterampilan peserta pelatihan sebesar $13,16 \%$ dibidang kompetensi kejuran Teknologi Otomotif.
\end{abstract}

Kata Kunci : Sekolah Menengah Kejuruan, Kualitas Lulusan, Kompetensi Kejuruan, Teknologi Otomotif.

\begin{abstract}
Vocational High School aims to be able to prepare creative students, master science and technology, and have competencies that are in line with the demands of the workforce. The quality of SMK graduates is not only determined by the individual factors of the students themselves, but also very much determined by external factors, one of which is educational competence that can prepare graduates in accordance with the demands of the workforce. The Community Science and Technology Program (IbM) aims to provide training in Automotive Technology Vocational Competencies for teachers and vocational students in Solok regency, IbM activities with the theme of Improving Vocational Competence in Automotive Technology for Teachers and Vocational Students, can increase training participants' knowledge and skills by $13.16 \%$ in the Automotive Technology competition competency.
\end{abstract}

Keywords : Vocational High School, Quality of Graduates, Vocational Competencies Automotive Technology.

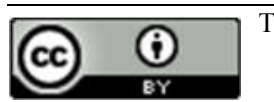

This is an open access article distributed under the Creative Commons 4.0 Attribution License

\section{Pendahuluan}

SMK membekali siswanya dengan sederet ilmu praktis untuk mencetak tenaga kerja siap pakai yang terampil. Istilah kejuruan berhubungan erat dengan karir. Sekolah kejuruan juga dapat dipandang sebagai pendidikan teknis yang secara langsung mengembangkan keahlian siswanya dalam bidang tertentu. Undang-undang Nomor 20 Tahun 2003 tentang Sistem Pendidikan Nasional dalam penjelasan pasal 15 menyebutkan bahwa pendidikan kejuruan merupakan pendidikan yang mempersiapkan peserta didik terutama untuk bekerja dalam bidang tertentu. Peraturan Pemerintah Nomor 29 Tahun 1990 tentang Pendidikan Menengah, Pasal 1 ayat 3 menyebutkan pendidikan kejuruan adalah pendidikan pada jenjang menengah yang mengutamakan pengembangan kemampuan siswa untuk melaksanakan jenis pekerjaan tertentu.

Sekolah Menengah Kejuruan mampu menyiapkan peserta didik yang kreatif, menguasai ilmu pengetahuan dan teknologi, serta memiliki 
kompetensi yang sesuai dengan tuntutan dunia kerja. Pendek kata, SMK tidak hanya membentuk kemampuan kognitif, lebih dari itu membentuk mentalitas peserta didik yang terintegralisasikan dengan baik kemampuan praktis, teoritis, maupun kompilasi keduanya. Dengan demikian Sekolah Menengah Kejuruan dapat menjembatani problematika dunia kerja tingkat menengah di Indonesia

Penyelarasan kompetensi lulusan SMK terhadap kebutuhan DU/DI tidak terlepas dari sumber daya yang ada disekolah tempat mereka menimba ilmu. Sekolah-sekolah yang sudah mapan dan sudah lama berdiri, dari segi peralatan praktekum yang digunakan untuk materi pembelajaran yang sesuai dengan kisi-kisi Lomba Kompetensi Siswa (LKS) Akan tetapi berbeda kondisinya dengan sekolah-sekolah yang ada di daerah-daerah terpencil, seperti di kabupaten Solok. Hasil observasi yang telah penulis lakukan pada beberapa SMK yang ada di kabupaten Solok, yaitu di SMK Negeri 1 Pantai Cermin dan SMK Negeri 1 Gunung Talang kabupaten Solok, kami menemukan beberapa aspek yang menghambat program SMK bisa, yaitu : kondisi workshop jurusan teknik otomotif yang belum tertata dengan baik dan belum sesuai dengan standar pelayanan minimal (SPM) workshop Sekolah Menengah Kejuruan (SMK), kondisi peralatan praktek juga belum lengkap dan beberapa peralatan sudah rusak dan tidak dapat digunakan untuk pembelajaran praktekum, kemampuan guru-guru jurusan otomotif yang masih kurang dalam penguasaan teknologi terbaru di bidang otomotif, juga rendahnya motivasi guru-guru dalam proses kegiatan belajar mengajar. Selain itu juga dalam hal kaitannya dengan Lomba Kompetensi Siswa (LKS), yang rutin dilombakan setiap tahun, dimana perlombaan LKS dimulai dari tingkat kabupaten, tingkat provinsi, dan tingkat nasional, di kedua sekolah mitra tidak mengikuti kegiatan LKS tersebut, dan tidak adanya keinginan pada guru dan siswa untuk mengikuti kegiatan LKS, karena kondisi peralatan yang tidak lengkap dan kompetensi guru yang tidak kompeten.

SMK Negeri 1 Pantai Cermin kabupaten Solok merupakan sekolah yang menyiapkan lulusannya mencapai lulusan yang memenuhi tuntutan dari tujuan pendidikan SMK yang telah ditetapkan oleh pemerintah. Kualitas lulusan SMK tidak hanya ditentukan oleh faktor individu dari siswa itu sendiri, akan tetapi juga sangat ditentukan oleh faktor dari luar, salah satunya komptensi pendidikan yang bisa menyiapkan lulusan sesuai dengan tuntutan dunia kerja.
SMK Negeri 1 Pantai Cermin yang merupakan salah satu SMK Kelompok Teknologi dan Rekayasa serta kelompok Tata Niaga di Kabupaten Solok telah melakukan berbagai upaya untuk menghadapi tantangan tersebut. Disamping memperluas jangkauan dan daya tamping peserta didik juga menambah keterampilan guru serta menambah sarana dan prasarana pendidikan yang ada. Penambahan sarana peralatan itu dilakukan melalui dana APBD Provinsi, Komite Sekolah serta APBN Pusat.

Mengingat SMK N 1 Pantai Cermin termasuk Sekolah yang relatif baru dan merupakan salah satu SMK Kelompok Teknologi dan Rekayasa serta kelompok Tata Niaga yang berada di Kabupaten Solok maka semua kebijakan pemerintah daerah provinsi yang menyangkut pendidikan kejuruan selalu memprioritaskan SMK N 1 Pantai Cermin. Pada saat ini Sekolah Menengah Kejuruan Negeri 1 Pantai Cermin melaksanakan Kurikulum Tingkat Satuan Pendidikan (KTSP) dan Kurikulum Tahun 2013 yang berdasarkan kompetensi masing-masing.

Visi SMK Negeri 1 Pantai Cermin Kabupaten Solok" menghasilkan lulusan siap kerja, cerdas \& kompetetif " dengan indikator: Siap kerja : Menciptakan pembelajaran dengan budaya kompetitif dan bertanggung jawab serta membekali siswa memiliki kompetensi dibidang masingmasing keahlian. Cerdas: Cerdas secara spiritual dan cerdas secara kompetensi dengan menciptakan lingkungan sekolah yang kondusif, mencerminkan nilai-nilai keimanan dan ketakwaan tehadap Tuhan Yang Maha Esa. Menciptakan budaya 3S (Salam, Sapa, Senyum) dilingkungan sekolah. Menerapkan syariat-syariat Agama Islam dilingkungan sekolah dan kehidupan sehari-hari. Memprakarsai dan aktif untuk memperingati hari-hari besar agama dan kegiatan keagamaan lainnya. Menciptakan suasana pembelajaran yang kompetitif dan memberikan pengetahuan seluas mungkin untuk memberikan kesempatan siswa mengembangkan daya pikirnya. Kompetetitif: Mengembangkan kreatifitas bagi warga sekolah. Menciptakan peningkatan kesadaran, minat dan perhatian siswa dalam mengikuti pembelajaran. Menumbuhkan semangat keunggulan secara intensif pada warga sekolah.

\section{StUdi PUSTaka}

Pada motor bensin, sistem pengaturan bahan bakar pada kendaraan bermotor telah mengalami peningkatan secara signifikan. Pengaturan tersebut bertujuan untuk mendapatkan pola penyemprotan bahan bakar agar dapat bercampur dengan udara 
secara homogen. Campuran yang homogen pada ruang bakar dapat menyebabkan proses pembakaran yang lebih sempurna sehingga menghasilkan emisi gas buang lebih sedikit. [1].

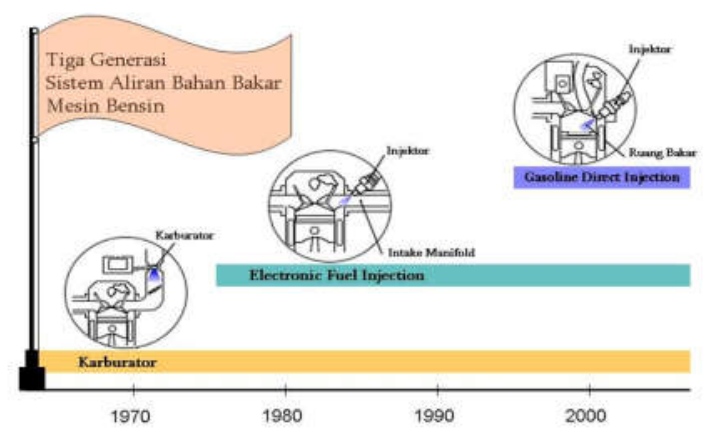

Gambar 1. Tiga generasi sistem bahan bakar

Gambar 1 di atas dapat diketahui, awal metode pemasukan bahan bakar kedalam ruang bakar di pada Tahun 1970 hingga 1980 sistem pemasukan bahan bakar kedalam ruang bakar mengunakan sistem karburator. Sistem karburator mencampur udara dan bahan bakar terjadi di dalam karburator. Seiring dengan regulasi emisi gas buang, proses pencampuran udara dan bahan bakar mengalami peningkatan pola pengaturannya. Mulai pada Tahun 1970 an, sistem pencampuran udara dan bahan bakar melahirkan satu generasi pola pengaturan baru yang di sebut dengan Electronic Fuel Injection (EFI) (TTA: 2010). [2].

Sistem EFI mengunakan konsep pencampuran udara dan bahan bakar terjadi pada saluran masuk (intake manifold) dengan mengunakan sebuah injektor untuk menyemprotkan bahan bakarnya. Pola pengaruran saat penyemprotan bahan bakar ke dalam intake manifold diatur oleh sebuah Electronic Control Unit (ECU). ECU akan mendapatkan beberapa sensor untuk meyemprotkan bahan bakar dengan saat dan jumlah yang tepat sesuai dengan putaran mesin. Perbandingan jumlah bahan bakar dan udara yang sesuai akan menyebabkan terjadinya pembakaran yang sempurna untuk menghasilkan tenaga yang optimal dan emisi gas buang yang ramah lingkungan. Hampir seluruh kendaraan terbaru telah mengunakan sistem EFI.

Pada pertengahan Tahun 1990 an, dengan tuntutan emisi gas buang kendaraan yang rendah, pola pengaturan pencampuran bahan bakar mengalami berkembang dengan munculnya Gasolin Direct Injection (GDI). Pada sistem GDI, pencampuran udara dan bahan bakar terjadi langsung pada ruang bakar. Konsep kerja sistem
GDI hampir sama dengan sistem pencampuran udara dan bahan bakar pada motor diesel. Hanya pada sistem GDI ini, proses pembakaran udara dan bahan bakar masing mengunakan busi sebagai penghasil percikan bunga api. Pada sistem EFI terdapat dua jenis sistem yaitu L-EFI dan D-EFI. Perbedaan mendasar pada kedua sistem tersebut adalah pada L-EFI terdapat sebuah sensor pengukur jumlah udara yang masuk kedalam intake manifold (Mass Air Flow Sensor). Sedangkan pada D-EFI terdapat sensor tekanan udara pada intake manifold (Manifold Absolute Pressure).

\section{Electronic Fuel Injection (EFI)}

Sistem injeksi elektronis yang lebih terkenal dengan sebutan Electronic Fuel Injection (EFI), volume penyemprotan bahan bakar dikontrol secara elektronik. Basis dari sistem ini mengalami banyak pengembangan dan juga banyak dipakai pada berbagai merek kendaraan, baik kendaraan keluaran Eropa, Jepang maupun Amerika. Bekerjanya injektor penyemprot bahan bakar diatur oleh sebuah Electronic Control Unit (ECU) yang lebih dikenal dengan ECM (Electronic Control Module)[2].

Perangkat pengontrol elektronik ini menerima beberapa masukan dari sensor-sensor antara lain sensor volume dan suhu udara yang masuk ke intake manifold, suhu air pendingin, beban dan putaran motor, posisi katup gas dan lain-lain sehingga volume penyemprotan bahan bakar dapat disesuaikan secara tepat berdasarkan berbagai masukan/input yang diterima oleh ECU tersebut. Contoh beberapa kendaraan yang menerapkan prinsip injeksi elektronis adalah daihatsu Xenia, toyota avanza, innova, mitsubishi lancer dan lain sebagainya. [3]

Prinsip dasar sistem bahan bakar pada mesin EFI adalah Sistem aliran bahan bakar dengan tekanan kerja tertentu melalui pompa bensin mensuplai bensin dari tangki, sampai ke injektor. Injektor menyemprotkan bensin ke setiap saluran masuk silinder motor, dengan jumlah bahan bakar yang disesuaikan dengan kebutuhan unjuk kerja (performa) motor. Electronic Control Unit (ECU/ECM) berfungsi mengatur volume penyemprotan bensin berdasarkan masukan dari sensor-sensor seperti sensor putaran, beban motor, situasi kerja (pengendalian motor), suhu air pendingin dan suhu udara masuk serta variabel lainnya.[4]

Keuntungan sistem EFI bila di banding dengan karburator 
1) Tanpa karburator memungkinkan saluran masuk/isap silinder motor dibuat lebih rata dan sama panjang, dengan demikian setiap silinder akan menerima jumlah campuran bahan bakar yang sama, akibatnya putaran motor lebih halus.

2) Konstruksi ruang bakar dan kepala slinder memungkinkan untuk lebih disempurnakan, agar effisiensi volumetrik motor lebih meningkat, untuk menambah torsi dan daya motor

3) Perbandingan campuran bensin udara yang dibakar dapat diusahakan selalu mendekati perbandingan campuran yang ideal dengan demikian emisi gas buang relatif lebih bersih.

4) Bila kadar racun pada emisi/gas buang dapat diperkecil karena campuran bensin dan udara dapat diatur mendekati perbandingan campuran yang ideal, secara otomatis bukan saja torsi serta daya motor dapat lebih meningkat akan tetapi pemakaian bensin tentu juga lebih hemat.

\section{Sistem Aliran Bahan Bakar pada Sistem} EFI

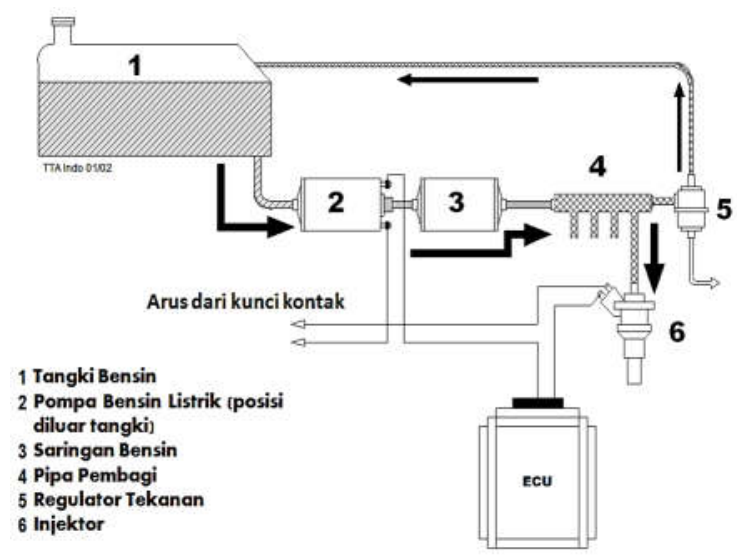

Gambar 2. Sistem pengaturan bahan bakar pada sistem EFI

Pada saat kunci kontak pada posisi ON, maka akan ada supply arus menuju ke ECU, Injektor dan pompa bensin. Ketika pada posisi ON pompa injeksi akan running (hidup) selama dua detik untuk mendapatkan supply bahan bakar pada pipa pembagi, agar pada saat kunci kontak pada posisi ST, engine dapat hidup dengan mudah. Pada saat mesin hidup pompa injeksi mengalirkan bahan bakar melewati saringan bahan bakar dan pipa pembagi. Pipa pembagi berfugsi sebagai sebagai pembagi bahan bakar ke masing-masing injektor. [5].

Untuk mengatur tekanan pada sistem EFI, terdapat regulator tekanan. Regulator tekanan akan mengalirkan bahan bakar return (kembali) ketangki bahan bakar apabila tekanan berlebih pada pipa pembagi. Untuk menyemprotkan bahan bakar kedalam intake manifold di atur oleh ECU. Sehingga saat ECU memberikan masukan arus maka injektor akan menyemprotkan bahan bakar ke dalam intake menifold.

Sistem EFI berdasarkan letak penginjeksiannya dapat di bagi menjadi 3, yaitu:

1. Throttle Body Injection (TBI)

2. Port Injection atau Multiple point Injection (MPI)

3. Direct Injection atau Gasoline Direct Injection (GDI)

Sedangkan berdasarkan cara penginjeksiannya, sistem EFI dapat di klasifikasikan menjadi 2, yaitu:

1. Continues time injection

2. Pulse time injection

Berdasarkan cara pengukuran udara masuk ke dalam intake manifold EFI dapat di bagi menjadi:

1. D - EFI

2. L - EFI

\section{Sistem Pengapian IIA- ESA}

Fungsi utama dari sistem pengapian adalah sebagai penyalur awal pembakaran sesuai dengan waktu pembakaran dan besar api yang di butuhkan. Pada sistem pengapian konvensional terdapat beberapa kelemahan, yaitu menurunkan performance dari sistem pengapian tersebut apabila telah dipakai dalam kurun waktu tertentu, bila putaran mesin bertambah, tegangan tinggi yang dihasilkan oleh ignition coil akan menurun. IIA adalah singkatan dari "Integrated Ignition Assembly", IIA menggabungkan igniter dan ignition coil dengan distributor, sedangkan pada "non IIA" di pasang secara terpisah.[6].

E S A

ESA adalah singkatan "Electronic Spark Advancer ". Dalam sistem ini harga saat pengapian optimum disimpan dalam engine control computer untuk setiap kondisi mesin. Sistem ini bekerja mendeteksi kondisi mesin (putaran mesin, aliran udara masuk, temperatur mesin dan lain-lain) berdasarkan sinyal dari setiap engine sensor, selanjutnya menentukan saat pengapian yang optimum sesuai dengan kondisi mesin dengan mengirim sinyal pemutus arus primer ke igniter yang mengontrol saat pengapian.

Dengan penggunaan electronik spark advance sistem, maka pick-up coil disatukan dalam distributor yang membangkitkan sinyal putaran mesin (sinyal $\mathrm{Ne}$ ) dan sinyal posisi sudut poros engkol sebagai pedoman ( $\mathrm{G}$ sinyal). Mekanisme vaccum controller dan governor tidak digunakan. 


\section{Sistem pengapian tanpa distributor (Distributor Less Ignition)}

Pada sistem pengapian transistor yang lama tegangan tinggi dibangkitkan oleh satu ignition coil yang didistribusikan ketiap busi oleh distributor. DLI adalah suatu sistem pengapian motor bensin yang tidak menggunakan distributor. Pada Toyota, sistem ini mempergunakan sebuah ignition coil untuk setiap dua buah busi. ECU (electric Controll Unit) mendistribusikan arus primer ketiap ignition coil secara langsung dan menyebabkan busi melompatkan bunga api.[7].

Pada sistem pengapian transistor, tegangan tingginya dibangkitkan oleh satu koil pengapian dan disalurkan kesetiap busi oleh distributor. DLI adalah suatu sistem pengapian motor bensin yang tidak menggunakan distributor. Sistem ini mengunakan sebuah koil pengapian untuk setiap dua buah busi atau satu koil pengapian untuk satu busi. Pada sistem pengapian ini, setiap busi memiliki koil pengapian tersendiri. ECU mengatur pemutusan arus primer ketiap koil pengapian secara langsung dan menyebabkan busi memercikkan bunga api. Urutan pengapian pada busi ditentukan oleh ECU. Saat arus negatif diberikan pada koil pengapian akan menyebabkan terjadinya induksi magnet. Dengan pengaturan ECU saat pengapian dalam ruang bakar akan terjadi secara teratur dengan waktu pembakaran yang sesuai.

\section{Dignosa Kerusakan Sistem EFI dengan Scan Tool}

Mekanisme pada kendaraan berkembang dengan cepat sekali untuk merespon tuntutan dan keinginan pelanggan. Tidak dapat dipungkiri lagi bahwa gas buang yang keluar dari kendaraan merupakan penyebab timbulnya polusi udara disamping asap rokok, gas beracun dari asap pabrik. Lembaga EPA (Environmental Protection Agency) dari Pemerintahan Amerika Serikat yang bertanggung jawab untuk mencegah timbulnya polusi udara, dan CARB (California air resources board) sudah membuat undang-undang yang membantasi emisi kendaraan dan hanya memperbolehkan menjual kendaraan yang sudah mengikuti aturan tersebut.

\section{Diagnosa On Board (OBD)}

OBD dikembangkan di USA untuk mencegah polusi udara, yang disebut dengan sistem pengukuran emisi gas buang. CVS (constant volume sampler) digunakan untuk memeriksa secara aktual berapa besar emisi gas yang keluar pada suatu kendaraan. Namun kesulitannya adalah perlu waktu yang lama untuk memeriksanya, karena itulah pemerintah Federal USA dan pemerintah California meminta untuk dapat dibuat alat yang dapat mengukur kadar emisi gas dengan lebih cepat. Sistem OBD-II sudah diwajibkan penerapannya untuk kendaraan produksi sejak tahun 1996, yang dipakai untuk memonitor emisi kendaraan tersebut.

OBD ditemukan oleh SAE (Society of Automotive Engineers) dengan melibatkan penyeragaman protokol kumunikasi komputer untuk kendraan yang dibuat oleh pabrik pembuat mobil, penyeragaman nama komponen, alat pengujian kerusakan, prosedur pengujian, penyeragaman diagnostic connector, dan fungsi standarisasi tes kerusakan. OBD-II mewajiban setiap kendaraan sudah mengadopsi fungsi-fungsi sebagai berikut: [8].

a. Standarisasi konektor diagnostic (16 pins)

b. Perluasan MIL (mal-function indicator lamp) indikator peringatan

c. Penyeragaman istilah kode kerusakan DTC (Diagnostic Trouble Code)

d. Parameter pada saat itu (data list) di lengkapi dengan indikasi sistem kontrol emisi gas

e. Kendala protokol komunikasi tidak lebih dari tiga

f. Dilengkapi dengan freeze frame (menyimpan data di ECU jika ada kode DTC yang timbul)

g. Monitoring secara berluanjut atau berkala terhadap sitem kontrol emisi yang secara kontinyu dapat memonitor suplai bahan bakar, sensor oksigen, dan kontrol sistem lainnya.

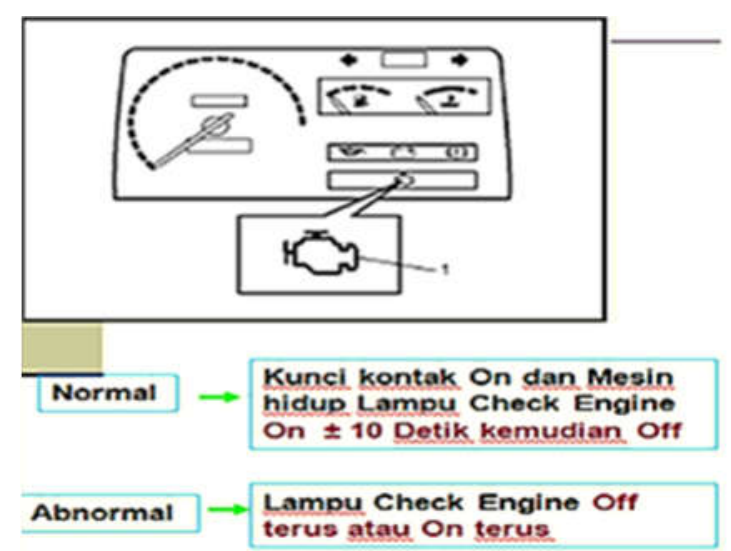

Gambar 3. On Board Diagnostic (OBD)

\section{Menggunakan Alat Pendeteksi (Scan Tool)}

Dengan menghubungkan alat pendeteksi ke DLC pada kendaraan maka alat pendeteksi tersebut dapat berkomunikasi dengan komputer (ECU) 
mesin. Apapun yang ingin kita ketahui kondisi kerja mesin dapat dilihat pada alat pendeteksi. Termasuk kerusakan kerusakan nya.[8].

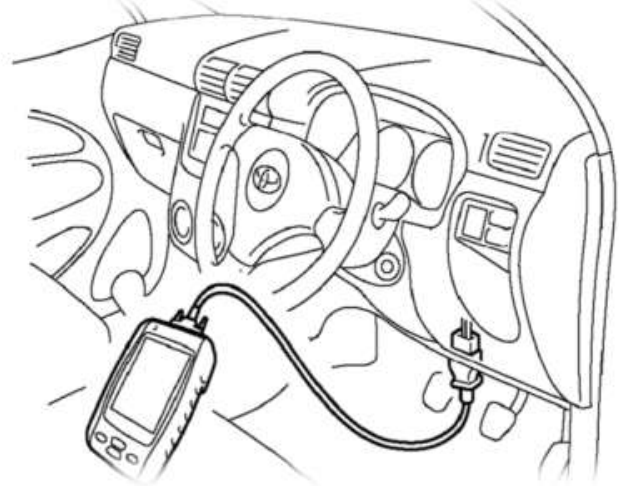

Gambar 4. Pemasangan Scantool pada DLC

Scan tool adalah alat untuk diagnosa yang dapat dipegang dan dirancang secara khusus untuk menolong memeriksa sistem komputer (elektronik) pada kendaraan. Alat ini kadangkala dihidupkan melalui (cigaratte lighter) kendaraan atau langsung melalui konektor DLC dan menggunakan mass storage cartridge (MSC) untuk menyimpan perubahan program perangkat lunak. Biasanya layar tampilan akan memudahkan untuk mengikuti instruksi dan menu-menu yang diinginkan dapat diperintahkan melalui tombol.[9].
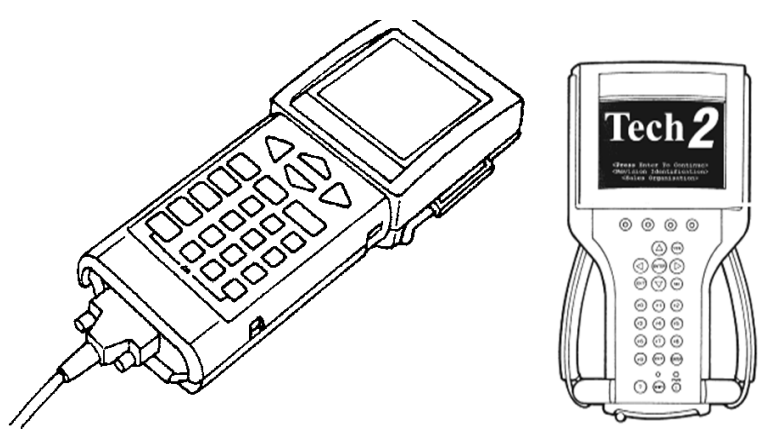

Gambar 5. Beberapa Jenis Scantool

\section{METODE}

Penelitian ini merupakan penelitian terapan yang mempunyai tujuan untuk meningkatkan kompetensi kejuruan teknologi otomotif bagi guru dan siswa SMK program studi Teknik Otomotif di SMK kabupaten Solok. Pelatihan ini merupakan upaya pelayanan bagi guru-guru dan siswa, khususnya pemberian materi dan kompetensi yang dilombakan dalam Lomba Kompetensi Siswa (LKS) SMK tingkat kabupaten dan tingkat provinsi.
Untuk melaksanakan kegiatan pengabdian Iptek Bagi Masyarakat (IbM) dengan pertimbangan dari pihak sekolah, kegiatan pelatihan dilaksanakan selama 4 (empat) hari dengan pelaksanaan dilakukan pada hari kamis, jumat, sabtu dan minggu. Metode yang disepakati bersama untuk pencapaian target kegiatan pengabdian Iptek Bagi Masyarakat (IbM) adalah:

\section{Metode ceramah dan tanya jawab}

Metode ini digunakan untuk menjelaskan pengetahuan dan memperkenalkan jenis keterampilan yang akan diberikan.. Dalam Metode ini akan disampaikan materi Sistem Bahan Bakar Bensin Injeksi Elektronik (Sistem EFI: Electronic Fuel Injection), Sistem Pengapian Elektronik, Overhoul dan pengukuran komponen engine, perawatan dan perbaikan sistem rem, perawatan dan perbaikan transmisi manual, dan diagnosa kerusakan sistem EFI dengan menggunakan Scan tools, serta pengukuran kandungan emisi gas buang dengan menggunakan four gas analyzer.

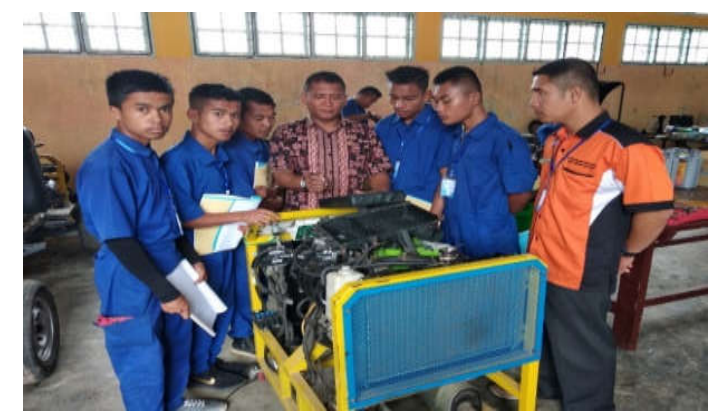

Gambar 6. Penyampaian Materi pelatihan

\section{Metode diskusi dan demontrasi}

Metode ini digunakan setelah tim pelaksana selesai menyajikan materi, selanjutnya dilakukan demontrasi atau peragaan dihadapan peserta, dan peserta pelatihan memahami modul petunjuk praktekum. Semua peserta diarahkan untuk mempelajari modul dan dilakukan diskusi terhadap materi yang kurang dipahami.

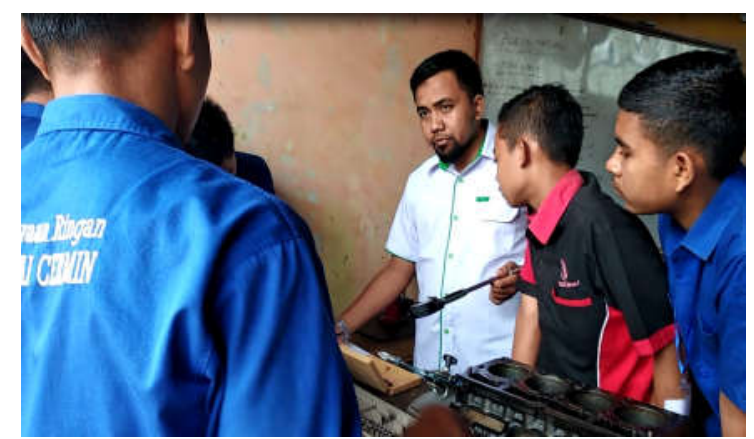

Gambar 7. Demontrasi pengukuran Komponen Engine 


\section{Metode praktikum}

Metode ini digunakan memberikan pengetahuan dan keterampilan kepada mitra untuk memperagakan bagaimana cara melakukan pekerjaan perawatan dan perbaikan yang dilakukan dalam kegiatan Lomba Kompetensi Siswa (LKS), yang terdiri dari : Tune up engine EFI, Overhoul dan pengukuran komponen engine, Perawatan Transmisi, Perawatan Sistem Rem, Merangkai Sistem Penerangan, dan Perawatan sistem pengisian.

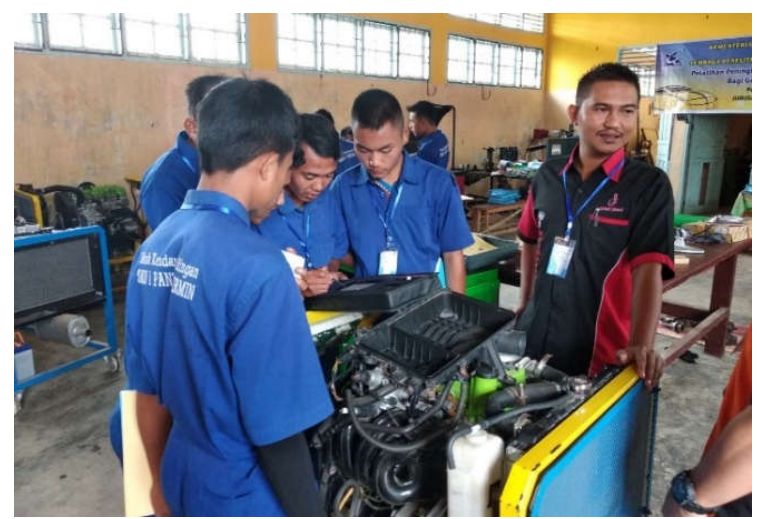

Gambar 8. Peserta pelatihan sedang melakukan Praktekum Engine EFI

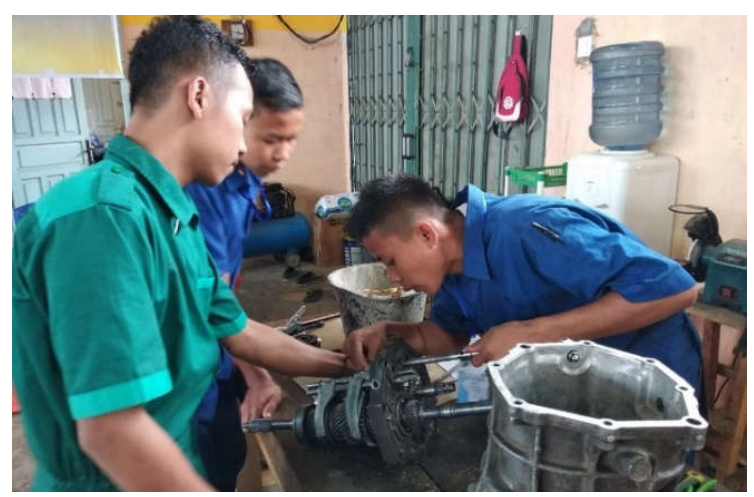

Gambar 9. Peserta pelatihan sedang melakukan pratikum transmisi manual

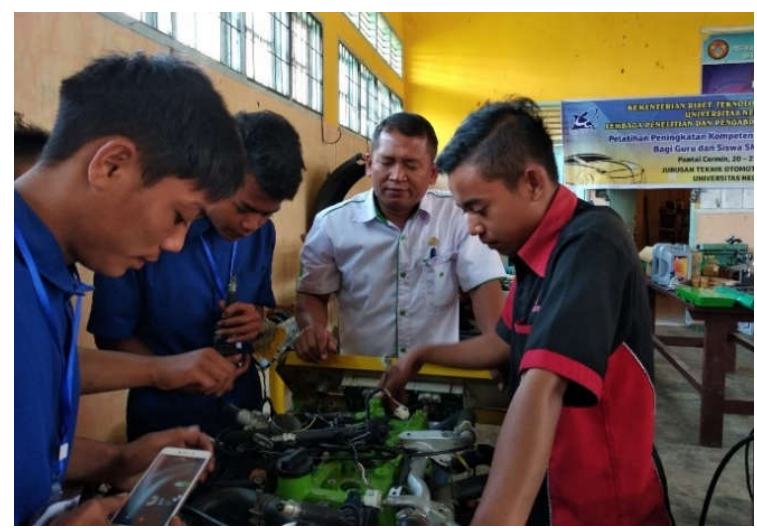

Gambar 10. Guru dan siswa sedang melakukan praktikum Engine EFI

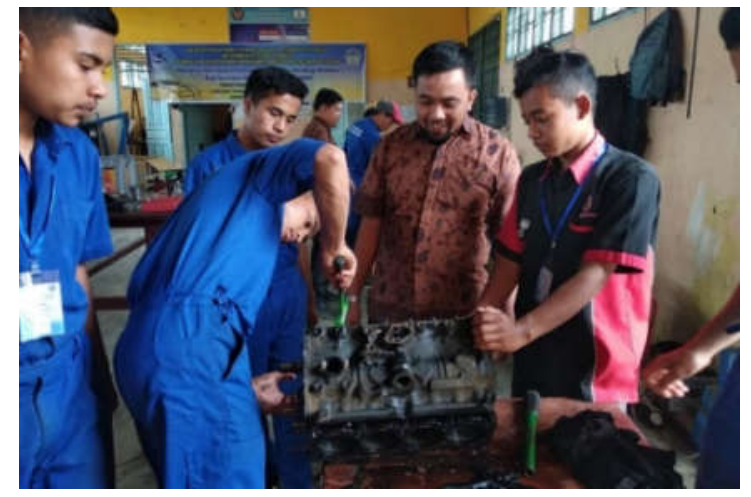

Gambar 11. Siswa sedang melakukan pembongkaran Komponen-komponen engine

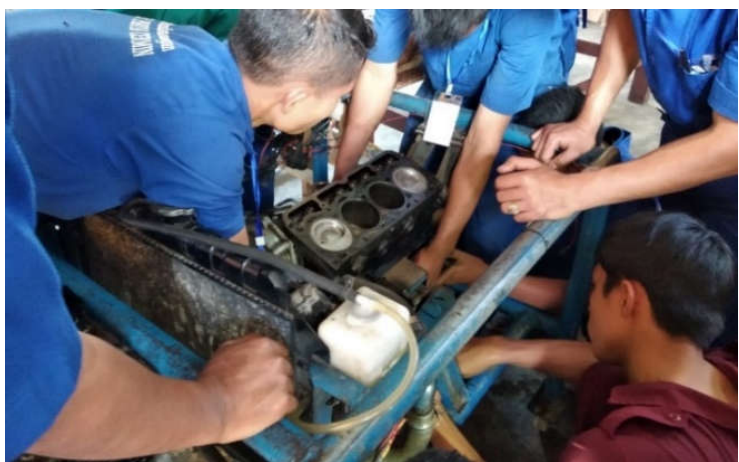

Gambar 12. Siswa sedang melakukan Pemasangan Blok silinder pada stand engine

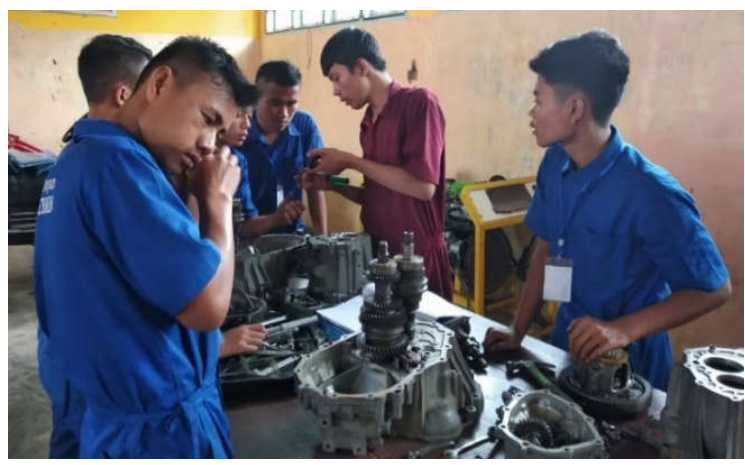

Gambar 13.Siswa sedang melakukan Pembongkaran komponen transaxle manual

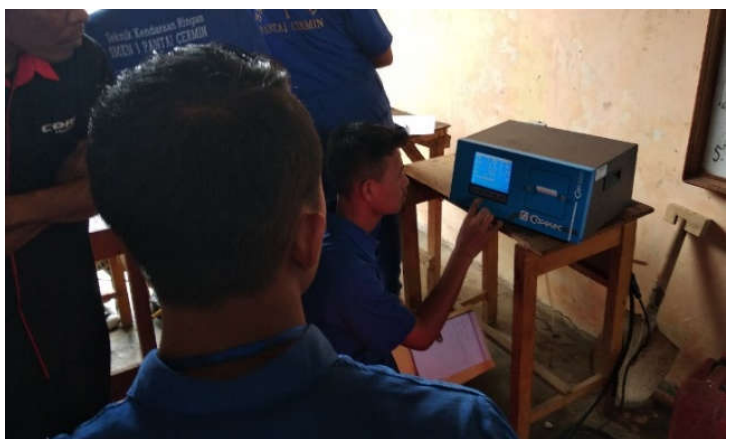

Gambar 14. Siswa dan guru sedang Melakukan pengukuran emisi gas buang. 
IV. HASIL DAN PEMBAHASAN

Untuk melihat hasil yang telah dicapai, dilakukan evaluasi saat kegiatan berlangsung dan akhir kegiatan pelatihan.

\section{A. Evaluasi saat kegiatan}

\section{Kehadiran}

Jumlah peserta yang mengikuti pelatihan adalah 24 orang dari 20 orang yang direncanakan. Semua peserta dapat mengikuti pelatihan dari awal kegiatan sampai akhir kegiatan, mulai pukul 08.00 sampai dengan 17.00 WIB. Semua peserta dapat mengikuti pelatihan dari awal sampai akhir kegiatan dengan penuh kedisiplinan. Pelatihan dilaksanakan selama 4 hari, tanggal 20, 21, 22, dan 23 September 2018. Meskipun pelatihan dilaksanakan pada hari sabtu dan minggu untuk hari ketiga dan hari keempat, peserta pelatihan tetap antusias dan semua peserta dapat mengikuti pelatihan dengan baik.

\section{Sikap dan antusiasme peserta pelatihan}

Selama pelatihan berlangsung sikap dan antusias peserta selama pelatihan sangat tinggi, peserta tidak ada yang meninggalkan pelatihan dan selalu disiplin mematuhi jadwal pelatihan yang telah dibuat. Bahkan jadwal pelatihan yang direncanakan awalnya hanya sampai jam 16.30, bertambah 30 menit, dikarenakan peserta sangat semangat untuk mencoba menggunakan engine sistem efi dan scan tool. Saat jam istirahat peserta pelatihan memanfaatkan waktu berdiskusi dengan instruktur dan memahami materi modul pelatihan dan modul praktikum. Panitia pelaksana pelatihan sangat kooperatif dan saling mendukung aktifitas dari peserta pelatihan. Semua panitia aktif membantu dalam keterlaksanaan kegiatan pelatihan.

\section{Keingintahuan peserta pelatihan sangat tinggi}

Hal ini terlihat dari pandangan peserta saat materi diterangkan, semuanya peserta bisa fokus dan kegiatan berjalan tertib seperti yang direncanakankan, yakni saat instruktur menerangkan materi, semua peserta harus memperhatikan instruktur dan materi, dan pada saat diberikan kesempatan untuk melakukan apa yang didemonstrasikan instruktur, peserta pelatihan dapat melihat modul yang sudah diberikan jikalau lupa langkah-langkah yang diterangkan instruktur ataupun bertanya kepada tim panitia.
Peserta pelatihan aktif selama pelatihan berlangsung

Selama kegiatan pelatihan berlangsung tidak ada peserta pelatihan yang berdiam diri; peserta pelatihan yang telah berhasil menyelesaikan tugasnya, mereka akan membantu peserta lain yang masih belum bisa. Hal ini juga memupuk semangat kebersamaan dan saling bantu membantu diantara peserta pelatihan, bahkan mereka menjadi saling kenal dan dekat meskipun sebelumnya mereka ada yang belum kenal karena asal sekolah yang berbeda.

\section{B. Evaluasi akhir kegiatan}

Evaluasi akhir kegiatan dilakukan dengan melihat hasil ujian yang dilakukan pada hari terakhir pelatihan. Hasil ujian dibandingkan dengan kemampuan awal peserta pelatihan sebelum pelatihan diberikan. Untuk memudahkan melihat apakah kegiatan ini memberikan dampak yang signifikan terhadap peserta, dapat dilihat pada Tabel 1.

Tabel 1. Hasil penilaian peserta pelatihan

\begin{tabular}{|c|l|c|c|c|}
\hline No & \multicolumn{1}{|c|}{ Nama } & $\begin{array}{c}\text { Nilai } \\
\text { Sebelum } \\
\text { Pelatihan }\end{array}$ & $\begin{array}{c}\text { Nilai } \\
\text { Sesudah } \\
\text { Pelatihan }\end{array}$ & $\begin{array}{c}\% \\
\text { Kenaikan }\end{array}$ \\
\hline 1 & Budi Hidayat & 66 & 74 & 12.12 \\
\hline 2 & Fadhillah Vemaindo & 67 & 75 & 11.94 \\
\hline 3 & Randa Surianto & 67 & 75 & 11.94 \\
\hline 4 & Hendri Agus Putra & 65 & 76 & 16.92 \\
\hline 5 & Alham Yuliadi & 68 & 76 & 11.76 \\
\hline 6 & Rivaldi & 70 & 77 & 10.00 \\
\hline 7 & Andika Survadi & 75 & 83 & 10.67 \\
\hline 8 & Ahmad Fauzan & 72 & 80 & 11.11 \\
\hline 9 & Adeka Putra & 67 & 75 & 11.94 \\
\hline 10 & Arya Prasetyo & 70 & 78 & 11.43 \\
\hline 11 & Agil Syaputra & 65 & 73 & 12.31 \\
\hline 12 & Afdal & 64 & 76 & 18.75 \\
\hline 13 & Nopendra Suriadi & 65 & 77 & 18.46 \\
\hline 14 & Rahmad Febrianto & 66 & 74 & 12.12 \\
\hline 15 & Nofrialdi & 67 & 76 & 13.43 \\
\hline 16 & Muhammad Irvan & 63 & 72 & 14.29 \\
\hline 17 & Yoki Saputra & 68 & 77 & 13.24 \\
\hline 18 & Dika Rahmadani & 63 & 70 & 11.11 \\
\hline 19 & Firdaus & 66 & 74 & 12.12 \\
\hline 20 & Andres & 62 & 72 & 16.13 \\
\hline 21 & Al Akbar, S.Pd & 75 & 85 & 13.33 \\
\hline 22 & Hafizh Alhadi, S.Pd & 77 & 88 & 14.29 \\
\hline 23 & Masrianto Tanjung, S.Pd & 70 & 79 & 12.86 \\
\hline 24 & Tomy Chandra, S.Pd & 74 & 84 & 13.51 \\
\hline & \multicolumn{1}{|c|}{ Rata-rata } & 68,00 & 76,92 & \\
\hline & & & $13.16 \%$ \\
\hline
\end{tabular}

Berdasarkan Tabel 1, terlihat terjadinya peningkatan kemampuan peserta pelatihan. Ratarata nilai peserta sebelum dilakukan pelatihan adalah 68,00 dan setelah dilakukan pelatihan kemampuan peserta meningkat menjadi 76,92. 
Artinya pelatihan yang diberikan dari tanggal 20, 21, 22, dan 23 September 2018 dapat meningkatkan kemampuan peserta sebesar 13,16 $\%$ dalam kompetensi kejuruan teknologi otomotif bagi guru dan siswa SMK di kabupaten Solok.

Selain itu, kegiatan pelatihan ini juga menghasilkan luaran berupa buku pedoman pelatihan teori dan praktikum, serta memberikan bahan praktikum berupa paking set, minyak pelumas dan silicon yang dapat digunakan peserta untuk bahan kegiatan praktikum.

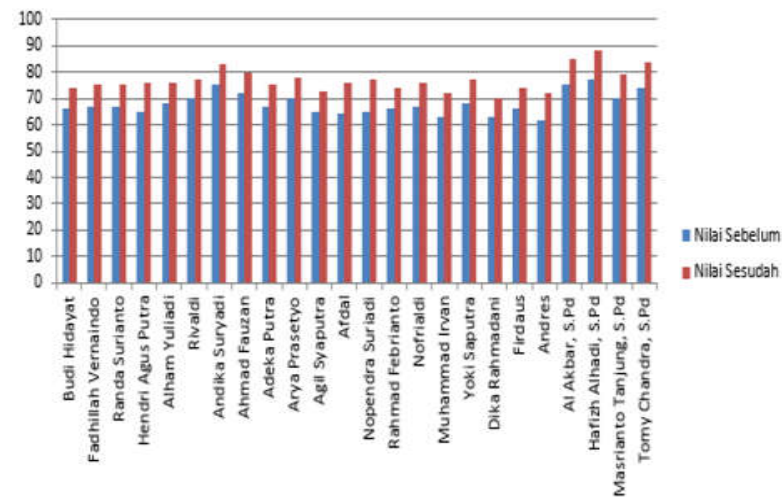

Gambar 16. Grafik Peningkatan Kemampuan Peserta Pelatihan

\section{Pembahasan}

Sasaran kegiatan pelatihan ini dapat dicapai sesuai dengan yang direncanakan dan diharapkan. Hal ini dapat dilihat dari hasil peningkatan nilai akhir pengetahuan dan ketrampilan yang telah diperoleh oleh peserta pelatihan. Peserta pelatihan mampu melakukan pekerjaan tune up engine EFI sesuai dengan prosedur dan pedoman penilaian dalam lomba kertrampilan siswa (LKS). Peserta pelatihan juga mampu melakukan pembongkaran dan pemasangan serta menghidupkan kembali engine seri $7 \mathrm{~K}$, Sebelum dilakukan pemasangan komponen engine peserta juga mampu melakukan pengukuran komponen engine dengan benar sesuai dengan pedoman penilaian. Peserta pelatihan juga dapat melakukan pembongkaran dan pemasangan serta pengukuran komponen transmisi manual dan transaxle manual dengan benar sesuai dengan pedoman penilaian dan standar operasional prosedur (SOP).

Selama mengikuti kegiatan pelatihan peserta memiliki kedisiplinan dan antusias dalam mengikuti pelatihan. Peserta pelatihan juga memiliki rasa percaya diri yang tinggi terhadap kemampuan yang telah mereka miliki. Hal ini dapat terlihat dari antusiasme peserta pelatihan untuk melakukan diskusi dengan panitia mengenai diagnosa kerusakan yang terjadi pada engine dengan sistem EFI, dan diagnosa kerusakan tentang overhoul mesin seri $7 \mathrm{~K}$.

Peserta pelatihan juga berharap agar kegiatan pelatihan waktunya diperpanjang, sehingga semua peserta dapat melakukan overhoul dan pembongkaran engine seri $7 \mathrm{~K}$, karena hanya 2 kelompok yang dapat melakukan pekerjaan overhoul, sedang 2 kelompok yang lainnya belum dapat kesempatan. Karena terbatasnya waktu, peserta pelatihan merasa perlu untuk mempraktekkan kembali kompetensi-kompetensi yang dilombakan dalam lomba ketrampilan siswa.

Komunkasi antara instruktur dan pihak sekolah serta peserta pelatihan terus terjalin, sehingga proses transfer kemampuan kompetensi terus berlangsung. Hal ini dengan disediakannya waktu pendampingan bagi peserta pelatihan.

Kegiatan pelatihan diikuti oleh 24 orang peserta, yang terdiri dari 4 orang guru dan 20 siswa Program studi Teknik Otomotif SMK di Kabupaten Solok. Sasaran kegiatan pelatihan ini dapat dicapai sesuai dengan yang diharapkan, hal ini dapat dilihat pada hasil akhir nilai pengetahuan dan keterampilan yang telah diperoleh oleh peserta pelatihan. Mereka telah mampu melakukan pekerjaan perawatan dan perbaikan Teknologi Otomotif yang meliputi : Sistem Bahan Bakar Bensin Injeksi Elektronik (Sistem EFI: Electronic Fuel Injection), Tune up petrol engine EFI, pengukuran komponen mesin, pembongkaran dan pemeriksaan komponen transmisi dan tranaxle manual, pembongkaran dan pemeriksaan komponen sistem rem dan merangkai serta diagnosa kerusakan sistem pengisian. Peserta pelatihan mempunyai percaya diri yang tinggi terhadap kemampuan yang telah mereka miliki.

\section{KESIMPULAN}

Dalam kegiatan pelatihan peningkatan kompetensi kejuruan teknologi otomotif bagi guru dan siswa ini bertujuan untuk meningkatan kompetensi kejuruan bidang teknlogi otomotif. Selain itu juga memberikan motivasi bagi guru dan siswa untuk mempersiapkan diri untuk mengikuti Lomba Kompetensi Siswa (LKS) yang diselenggarakan secara rutin setiap tahun, mulai dari tingkat kabupaten/kota, provinsi dan tingkat nasional. Hasil di lomba LKS menjadi tolak ukur keberhasilan proses pembelajaran di Sekolah Menengah Kejuruan (SMK). Pelatihan peningkatan Kompetensi Kejuruan Teknologi Otomotif bagi Guru dan Siswa SMK, dapat meningkatkan pengetahuan dan keterampilan 
peserta pelatihan sebesar 13,16\% dibidang kompetensi kejuran Teknologi Otomotif.

\section{DAfTAR PUSTAKa}

[1] Purwanto, Wawan. Sugiarto, Toto. Fernandez, Donny. (2012). Analisa kerja Manifold Absolute Pressure (MAP) pada D-EFI dan Mass Air Flow Sensor (MAFS) pada L EFI serta emisi yang dihasilkan oleh kedua sistem EFI tersebut. Fakultas Teknik UNP. Hasil Penelitian FT UNP.

[2] Rasydah and Sugiarto, Toto. (2013). Analisa Kerja Manifold Absolute Pressure (Map) dan Kadar Kandungan Emisi Gas Buang yang Dihasilkan pada Motor Bensin dengan Sistem Injeksi Elektronik Type D-Efi. Jurnal Elektron , 5 (2). pp. 69-74. ISSN 2085-6989

[3] Sudarno, Putra Dwi. Sugiarto, Toto. Purwanto, Wawan. (2017). Analisa Rekarakterisasi Sensor Engine Coolant Temperature (ECT). Vol. 1, No.2. JIT Jurnal Ilmu Pengetahuan dan Teknologi. Politeknik Kota Malang. ISSN 2548-8686. ISSN Online 2548-8597. Hal. 40 - 46

[4] TTA. (2010). Dasar-Dasar Sistem EFI. Jakarta: PT. TTA International

[5] Sugiarto, Toto. Sudarno, Putra Dwi. dan Purwanto, Wawan. ( 2017). Effect of engine temperature changes on injection time of fuel and gas emission of gasoline engine. Prosiding.International Conference on Technical and Vocational Education and Training. Padang. Fakultas Teknik Universitas Negeri Padang. ISBN : 978-6021178-11-9

[6] Sugiarto, Toto. Sudarno, Putra Dwi. dan Purwanto, Wawan. ( 2017). Analysis on the role of engine coolant temperature sensor in gasoline engine. VANOS Jurnal of Mechanical Engineering Education. Vol.2, Nomor. 2, hal. 145 - 151. ISSN 2558 - 2611

[7] Toyota. (2010). Training Engine Step 1. Jakarta. PT. Toyota Astra Motor

[8] Daihatsu. (2010). Engine Step 1 Training. Jakarta. PT Daihatsu Astra Motor

[9] Toyota. (2008). Service Manual Toyota Kijang Innova . Jakarta. PT. Toyota Astra Motor

\section{BiodataPenulis}

Toto Sugiarto, lahir di Sukamandi, 13 Februari 1973, merupakan staf pengajar di jurusan Teknik Otomtif Fakultas Teknik Universitas Negeri Padang. Pendidikan S1 di Program Studi Pendidikan Teknik Otomotif, Fakultas Pendidikan Teknologi dan Kejuruan IKIP Padang dan S2 di Universitas Andalas dengan konsentrasi Perencanaan Pendidikan. Dengan ketertarikan riset di bidang Teknik Otomotif dan Pendidikan Vokasi serta Perencaan Pendidikan.

Bahrul Amin, lahir Palembang, 12 Februari 1963, merupakan merupakan staf pengajar di jurusan Teknik Otomtif Fakultas Teknik Universitas Negeri Padang. Pendidikan S1 di Program Studi Pendidikan Teknik Otomotif, Fakultas Pendidikan Teknologi dan Kejuruan IKIP Padang, S1 di STTP Padang, dan S2 Program Pascasarjana Universitas Negeri Padang. Dengan ketertarikan riset di bidang Teknik Otomotif dan Pendidikan Vokasi.

Wawan Purwanto, merupakan salah satu staf pengajar di Jurusan Teknik Otomotif Fakultas Teknik Universitas Negeri Padang. Menyelesaikan S1 dari program studi pendidikan Teknik Otomotif Fakultas Universitas Negeri Padang, kemudian mengambil S2 di Universitas Pancasila dan mendapatkan gelar doktoral dari National Kaohsiung First University of Science and Technology Taiwan. Memiliki ketertarikan riset di bidang Teknik Otomotif dan Motor Listrik.

Ahmad Arif, lahir di Padang Panjang, 27 Februari 1989, Pendidikan S1 di program studi Pendidikan Teknik Otomotif Jurusan Teknik Otomotif Fakultas Teknik Universitas Negeri Padang dan lulus tahun 2012. Tahun 2013 - 2015 melanjutkan pendidikan S2 di program studi Rekayasa Konversi Energi Jurusan Teknik Mesin Program Pascasarjana ITS Surabaya. Selanjutnya menjadi staf pengajar di Jurusan Teknik Otomtif FT UNP sejak tahun 2015 sampai sekarang.

Dwi Sudarno Putra, menyelesaikan pendidikan S1 di Universitas Gadjah Mada dan S2 di Universitas Indonesia. Saat ini aktif sebagai staf pengajar di Jurusan Teknik Otomotif Fakultas Teknik Universitas Negeri Padang. Dengan ketertarikan riset di bidang elektronika otomotif. 